\title{
Characterization of polysaccharides from Hypnea spinella (Gigartinales) and Halopithys incurva (Ceramiales) and their effect on RAW 264.7 macrophage activity
}

\author{
Roberto T. Abdala Díaz • Mariana Chabrillón • \\ Alejandro Cabello-Pasini • Juan Luis Gómez-Pinchetti • \\ Félix L. Figueroa
}

Received: 26 May 2010 /Revised and accepted: 18 October 2010

(C) Springer Science+Business Media B.V. 2010

\begin{abstract}
Red algae have been reported to be an important source of polysaccharides with potential immunomodulatory properties. The objective of this study was to characterize the polysaccharides from Halopithys incurva and Hypnea spinella and to evaluate their effect on the synthesis of cytokines by murine cell line RAW 264.7 macrophages. Polysaccharides were obtained by N-cetylpyridinium bromide precipitation and characterized by Fourier transform-infrared spectroscopy. Their effect on the activity of RAW 264.7 macrophages was examined by quantification of tumor necrosis factor (TNF)- $\alpha$, interleukin (IL)-6, and nitric oxide (NO) production using enzyme-linked immunosorbent assays. The activation of the cytokine IL- 6 and NO increased linearly as the concentration of polysaccharides from $H$. incurva and $H y$. spinella increased. In general, the activation of IL-6 and NO was tenfold greater when macrophages were
\end{abstract}

\author{
R. T. A. Díaz · F. L. Figueroa \\ Department of Ecology. Faculty of Sciences, \\ University of Málaga, \\ Campus de Teatinos, \\ 29071 Málaga, Spain \\ M. Chabrillón \\ Mediterranean Photobiology Center, \\ c/Prosper Merimeé 7, \\ 29007 Málaga, Spain \\ A. Cabello-Pasini $(\bowtie)$ \\ University of Baja California, \\ Ensenada, Baja California, Mexico \\ e-mail: acabello@uabc.edu.mx

\section{J. L. Gómez-Pinchetti} \\ Centro de Biotecnología Marina, \\ Universidad de Las Palmas de Gran Canaria, \\ Muelle de Taliarte s/n, \\ 35214 Telde, Las Palmas, Spain
}

exposed to polysaccharides from $H$. incurva than when exposed to polysaccharides from Hy. spinella. In contrast, TNF- $\alpha$ concentration did not increase when macrophages were exposed to increasing polysaccharide levels. These results indicate that polysaccharides are strong cytokine IL-6 inducers.

Keywords Polysaccharides · Immunomodulator . Macrophages · FT-IR spectroscopy

\section{Introduction}

For decades, red seaweeds have been an important source of metabolites for the food and non-food industry. Agar and carrageenan, for example, have been used as texturing agents in the food industry, while phenolic compounds have been used as antimicrobial agents in the pharmaceutical industry. Recently, polysaccharides from seaweeds have also been reported as having anticancer and antitumor properties. Specifically, the culturing of Hypnea spinella (Rhodophyta, Hypneaceae) and Halopithys incurva (Rhodophyta, Rhodomelaceae) have recently gained interest due to their production of metabolites with antimicrobial and antifungal activities. $H$. incurva synthesizes 2,3-dibromo-4,5-dihydroxybenzyl alcohol (lanosol), which has been shown to have high toxic effects on bacteria and other algae (Kladi et al. 2004). Furthermore, it has been reported that extracts from $H$. incurva exert antimicrobial activity against Staphylococcus aureus MB5393 (González del Val et al. 2001).

The genus Hypnea is an important source of polysaccharides used as gelling and thickening agents in food and nonfood industries (Andrade et al. 2000, Cordeiro et al. 2006). In 
addition to their emulsifying properties, polysaccharides and other metabolites with antibacterial and antitumor properties have been extracted from a number of Hypnea species. The cholesterol analog 22-dehydrocholesterol, for example, has been isolated from Hypnea japonica. This molecule has been shown to inhibit mouse fibroblast cells. Furthermore, the aqueous extracts of $H$. japonica, Hypnea musciformis, and Hypnea cervicornis have shown agglutinating activity against native and trypsin-treated rabbit erythrocytes (Ainouz and Sampaio 1991; Hori et al 1986, 2000). Two lectins with antifungal and antimicrobial activity have also been isolated from H. musciformis and H. cervicornis (Melo et al. 1997; Nagano et al. 2005; Cordeiro et al. 2006). It has been reported that the polysaccharide fractions from Hypnea charoides show high antiviral activity against type 1 and type $2 \mathrm{HSV}$, while maintaining low cytotoxicity levels (Smit 2004). The nucleoside 5-deoxy-5-iodotubercidin, isolated from Hypnea valentiae, strongly inhibits adenosine uptake in rat and guinea-pig brain slices and inhibits adenosine kinase obtained from guinea-pig brain and rat brain and liver. The same compound causes muscle relaxation and hypothermia when injected into mice (Davies et al. 1984).

Polysaccharides isolated from algae have been reported to modify macrophage activity, inducing the production of cytokines (Schepetkin and Quinn 2006) or to stimulate respiratory burst activity of turbot phagocytes (Castro et al. 2006). Macrophage defense against pathogens include cytokine secretions such as interleukin 6 (IL-6), tumor necrosis factor $\alpha$ (TNF- $\alpha$ ), and inflammation mediators like nitric oxide (NO). The primary role of TNF- $\alpha$ is the regulation of immune cells; however, it has also been shown to reduce viral replication. This cytokine is involved in systemic inflammation and stimulates the acute phase reaction. On the other hand, IL-6 is a multifunctional cytokine that regulates several immune responses, including acute phase reactions, and participates as a mediator of the inflammatory response. Its production is induced by several factors, including TNF- $\alpha$, IL- $1 \beta$, and bacterial endotoxin lipopolysaccharides (LPS; Martínez et al. 1998). Modulation of the macrophage function by seaweed polysaccharides has been shown to increase phagocytosis, microbicidal activity, chemotaxis, and antigen presentation to $\mathrm{T}$ cells, thus helping in preventive and therapeutic strategies against diseases (Desai et al. 2007). Consequently, the objective of this study was to characterize the polysaccharides from $H$. incurva and Hy. spinella and to evaluate their effect on the synthesis of cytokines by macrophages.

\section{Material and methods}

Hypnea spinella and Halopithys incurva from the east coast of Gran Canaria (Canary Islands, Spain, $28^{\circ} 00^{\prime} \mathrm{N} ; 15^{\circ} 22^{\prime}$
W) were cultivated in tanks at the greenhouse facilities of the Center of Marine Biotechnology in Taliarte (University of Las Palmas of Gran Canaria) during spring and summer of 2008. Effluents from fishponds, with ammonium concentrations ranging from 10 to $300 \mu \mathrm{M}$, were continuously pumped into the semicircular glass fiber seaweed tanks $\left(1.8 \mathrm{~m}^{2}, 0.75 \mathrm{~m}^{3}\right)$ under greenhouse conditions (receiving $80 \%$ of the total external PAR radiation and no UVR). Algal tissue was randomly selected after a cultivation period of 6 months and epiphyte-free fragments were freeze-dried and used for analysis.

Polysaccharides from $H$. incurva and Hy. spinella were obtained by homogenizing $10 \mathrm{~g}$ of dry tissue in $300 \mathrm{~mL}$ of distilled water. The solution was autoclaved $\left(115^{\circ} \mathrm{C}\right)$ for $20 \mathrm{~min}$ and then centrifuged $(10,000 \times \mathrm{g})$ for $15 \mathrm{~min}$. The pellet was re-suspended and re-extracted twice as described previously. Polysaccharides were extracted from the supernatant by selective precipitation with $2 \%(w / v)$ O-Ncetylpyridinium bromide (Cetavlon; Morris Quevedo et al. 2000). The precipitated acidic polysaccharide was purified with $4 \mathrm{M} \mathrm{NaCl}$, and the polysaccharide was flocculated again with $96 \%(v / v)$ ethanol, centrifuged $(10,000 \times g$ for $10 \mathrm{~min}$ ), dialyzed against $2 \mathrm{M} \mathrm{NaCl}$, and finally lyophilized. Stock solutions of polysaccharides from $H$. incurva and $H y$. spinella were prepared in dimethyl sulfoxide (DMSO) and stored at $-20^{\circ} \mathrm{C}$. The stock solution was diluted in Dulbecco's modified Eagle's medium (DMEM) just before use. The final concentration of DMSO was less than $0.1 \%$ and had no effect on cell proliferation. A solution containing DMSO in a similar concentration was used as control.

Fourier transform-infrared (FT-IR) spectra were obtained using a self-supporting pressed disk of the mixture of $\mathrm{Hy}$. spinella and $H$. incurva polysaccharide- $\mathrm{KBr}(1 \% w / w)$ and pressing the mixture into a $16-\mathrm{mm}$-diameter mold with a hydrostatic pressure of $15.0 \mathrm{t} \mathrm{cm}^{2}$ for $2 \mathrm{~min}$. The FT-IR spectra were collected on a Thermo Nicolet Avatar 360 instrument (Thermo Electron Inc., USA) with a resolution of $4 \mathrm{~cm}^{-1}$, equipped with a DTGS detector and OMNIC 7.2 software (bandwidth $50 \mathrm{~cm}^{-1}$, enhancement factor 2.6). Spectra were obtained in the $4,000-400 \mathrm{~cm}^{-1}$ region. Baseline adjustment was performed using the Thermo Nicolet OMNIC software to flatten the baseline on each spectrum. The OMNIC correlation algorithm was used to compare sample spectra to the spectral library (Thermo Fischer Scientific).

Murine macrophage cell line (RAW 264.7, ATCC, USA) was routinely cultured in DMEM supplemented with $10 \%$ fetal bovine serum, $2 \mathrm{mM}$ L-glutamine, 100 units $\mathrm{mL}^{-1}$ penicillin sodium, $0.1 \mathrm{mg} \mathrm{mL}^{-1}$ of streptomycin sulfate, and $0.25 \mu \mathrm{g} \mathrm{mL}^{-1}$ of amphotericin B. Cells were maintained subconfluent at $37^{\circ} \mathrm{C}$ in humidified air containing $5 \% \mathrm{CO}_{2}$. Cultured cells were harvested by gentle 
scraping. Cells were used when confluence had reached $75 \%$.

For the macrophage proliferation assay RAW $264.7(5 \times$ $10^{3}$ cells well $^{-1}$ ) cells were incubated with different concentrations of polysaccharides $\left(0-100 \mu \mathrm{g} \mathrm{mL} \mathrm{mL}^{-1}\right)$ for $48 \mathrm{~h}$ at $37^{\circ} \mathrm{C}$ and $5 \% \mathrm{CO}_{2}$. Macrophage proliferation was estimated by the MTT (3-(4,5-dimethylthiazol-2-yl)-2,5diphenyl tetrazolium bromide) assay. Briefly, a volume of $10 \mu \mathrm{L}$ of the MTT solution (5 $\mathrm{mg} \mathrm{mL}^{-1}$ in PBS) was added to each well, and plates were incubated at $37^{\circ} \mathrm{C}$ for $4 \mathrm{~h}$. The yellow tetrazolium salt of MTT is reduced by mitochondrial dehydrogenases in metabolically active cells to form insoluble purple formazan crystals, which are dissolved by the addition of acid-isopropanol $(100 \mu \mathrm{L}$ of $0.04 \mathrm{~N} \mathrm{HCl}$ in isopropanol). The absorbance at $550 \mathrm{~nm}$ was read in a microplate reader (Whittaker Bioproducts, USA), and the relative cell viability was expressed as the mean percentage of viable cells compared with untreated cells.

For cytokine determination, RAW cells were cultured in the presence of different concentrations of the polysaccharides $\left(0-100 \mu \mathrm{g} \mathrm{mL}^{-1}\right)$ in a 24 -well microtiter plate $\left(5 \times 10^{5}\right.$ cells well $\left.{ }^{-1}\right)$ in a total volume of $1 \mathrm{~mL}$. LPS (50 $\mathrm{ng} \mathrm{mL} \mathrm{m}^{-1}$ ) was used as positive control for macrophage activation. Cells were incubated for $48 \mathrm{~h}$, and the supernatant was collected and used to determine cytokine production following stimulation by the polysaccharides. Production of TNF- $\alpha$ and IL- 6 was measured by sandwich enzyme-linked immunosorbent assays as described by Martínez et al. (1998). Briefly, a purified rat anti-mouse monoclonal TNF- $\alpha$ or IL- 6 antibody $(0.5 \mathrm{mg}$, BD Pharmingen) was used for coating at $2 \mu \mathrm{g} \mathrm{mL} L^{-1}$ at $4^{\circ} \mathrm{C}$ for $16 \mathrm{~h}$. After washing and blocking with phosphate-buffered saline (PBS) containing 3\% bovine serum albumin, culture supernatants were added to each well for $12 \mathrm{~h}$ at $4^{\circ} \mathrm{C}$. Unbound material was washed off and a biotinylated monoclonal anti-mouse TNF- $\alpha$ or IL-6 antibody (0.5 mg, BD Pharmingen) was added at $2 \mu \mathrm{g} \mathrm{mL}^{-1}$ for $2 \mathrm{~h}$. Bound antibody was detected by addition of avidinperoxidase (SIGMA) for $30 \mathrm{~min}$, followed by addition of the ABTS substrate solution. Absorbance at $405 \mathrm{~nm}$ was taken $10 \mathrm{~min}$ after the addition of the substrate. A standard curve was constructed using various dilutions of recombinant murine TNF- $\alpha$ or IL-6 in PBS containing 10\% FCS. The amount of each cytokine in the culture supernatants was determined by extrapolation of absorbances to the standard curve.

Nitrite accumulation was used as an indicator of NO production in the medium. The cell-free supernatant $(90 \mu \mathrm{L})$ was incubated with the same volume of Griess reagent $(1 \%(w / v)$ sulfanilamide, $0.1 \%(w / v)$ naphthylenediamine dihydrochloride, $\left.0.5 \%(v / v) \mathrm{H}_{3} \mathrm{PO}_{4}\right)$ at room temperature for $5 \mathrm{~min}$, and the absorbance at $550 \mathrm{~nm}$ was determined using a microplate reader. The concentration of $\mathrm{NO}_{2}$ was determined by a least squares linear regression analysis using $\mathrm{NaNO}_{2}$ to generate a standard curve.
The data are presented as means \pm standard deviations of three experiments $(n=3)$. Statistical differences between treatments were performed using Student's $t$ test for paired comparisons. Statistically significant differences were considered at $P<0.05$.

\section{Results}

The polysaccharides characterized by FT-IR spectroscopy from both red algae showed similar patterns from 4,000 to $1,500 \mathrm{~nm}$ (Fig. 1). However, the polysaccharide spectra from both seaweeds showed significant differences in peaks from 1,500 to $500 \mathrm{~nm}$. Both polysaccharides showed an intense broad stretching peak at around $3,384 \mathrm{~cm}^{-1}$ and a stretching band at $2,930 \mathrm{~cm}^{-1}$. Peaks in the polysaccharides from both seaweeds were also observed at 2,069, 1,642, $1,013-1,153$, and $1,240 \mathrm{~cm}^{-1}$.

The proliferation of RAW macrophages was not affected by the addition of the polysaccharides $\left(0\right.$ to $\left.100 \mu \mathrm{g} \mathrm{mL}^{-1}\right)$ to the culture medium (data not shown). In contrast, the production of IL-6 increased linearly as the $H$. incurva polysaccharide concentration increased (Fig. 2). The levels of IL-6 started to saturate when the polysaccharide concentration increased above $50 \mu \mathrm{g} \mathrm{mL}^{-1}$ (Fig. 2). The production of IL-6 by polysaccharides extracted from $\mathrm{Hy}$. spinella is very low, less than $0.25 \mathrm{ng} \mathrm{mL} \mathrm{m}^{-1}$. The production of IL-6 was tenfold greater $(P<0.05)$ when RAW macrophages were exposed to increasing concentrations of polysaccharides from $H$. incurva than that from Hy. spinella. In contrast to the IL-6 concentration, increasing levels of polysaccharides from $H$. incurva and $H y$. spinella did not induce TNF- $\alpha$ production (data not shown). The control treatment of RAW cells with LPS (50 ng $\mathrm{mL}^{-1}$ ) caused a significant increase in the

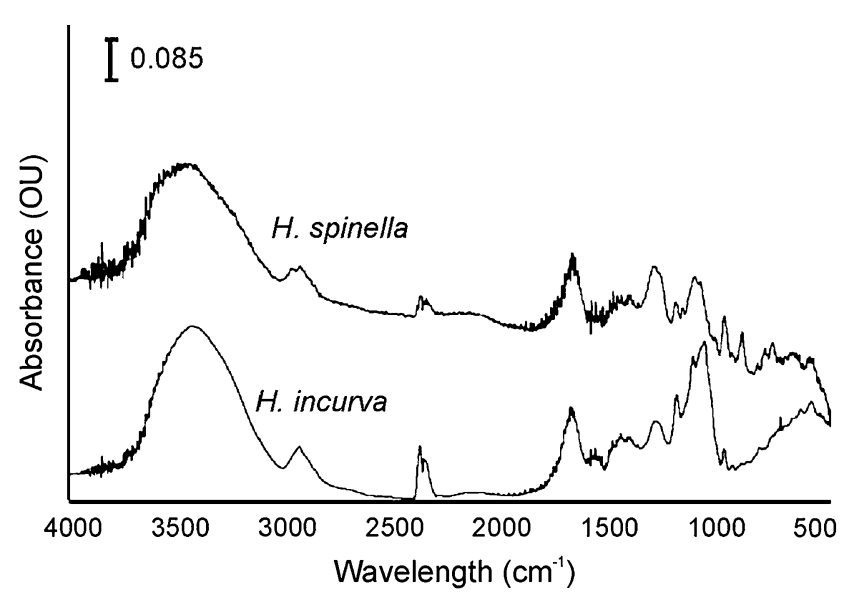

Fig. 1 Infrared spectrum of the polysaccharide fraction isolated from Hypnea spinella and Halopithys incurva 


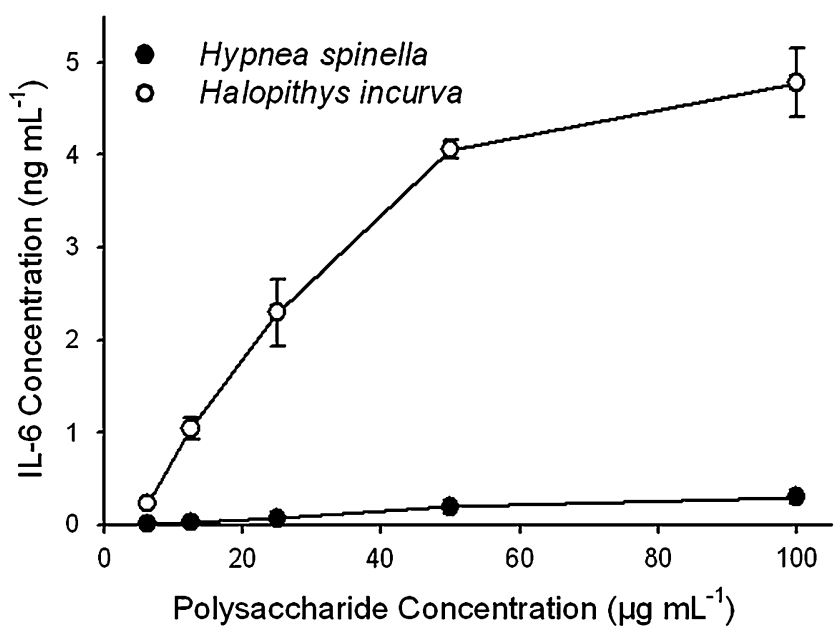

Fig. 2 Production of interleukin (IL-6) by RAW macrophages exposed to different concentrations of polysaccharides from Hypnea spinella and Halopithys incurva. Data points represent the average of three samples \pm SD. Error bars not shown are smaller than the symbol size

production of TNF- $\alpha$ reaching a value of $23.6 \pm$ $3.8 \mu \mathrm{g} \mathrm{mL}^{-1}$.

Similar to the increase of production of IL-6, polysaccharide extracted from $H$. incurva increased $\mathrm{NO}$ production (Fig. 3). There was a tenfold greater $(P<0.05)$ response in NO concentration when RAW macrophages were exposed to polysaccharides from $H$. incurva than when they were exposed to polysaccharides from Hy. spinella. The NO production in $H$. incurva was low when polysaccharide levels were below $15 \mu \mathrm{g} \mathrm{mL}^{-1}$; however, NO production increased linearly when polysaccharide levels increased above $20 \mu \mathrm{g} \mathrm{mL}^{-1}$. In contrast to the production of NO in $H$. incurva, the NO production in Hy. spinella remained relatively low throughout the experiment.

\section{Discussion}

The FT-IR spectra suggest that $H y$. spinella and $H$. incurva have different polysaccharides in their cell wall mainly by the different absorption in the range of 1,500 to $500 \mathrm{~nm}$. The broad stretching peak around $3,384 \mathrm{~cm}^{-1}$ is characteristic of the hydroxyl group, while the weak stretching band at 2,930 $\mathrm{cm}^{-1}$ suggests $\mathrm{C}-\mathrm{H}$ bonds. In contrast, the peak at $2,069 \mathrm{~cm}^{-1}$ has been shown to indicate the presence of aliphatic C-H bonds (Pereira et al 2009). The peak at around 1,642 $\mathrm{cm}^{-1}$ and the peaks near 1,013.29$1,153.67 \mathrm{~cm}^{-1}$ suggest the presence of the $\mathrm{C}-\mathrm{O}$ group. On the other hand, the peak of strong intensity at $1,240 \mathrm{~cm}^{-1}$ could be attributed to the $\mathrm{S}=\mathrm{O}$ (ester sulfate; Mollet et al 1998) stretching vibration, which is associated with the spatial distribution of sulfated groups.

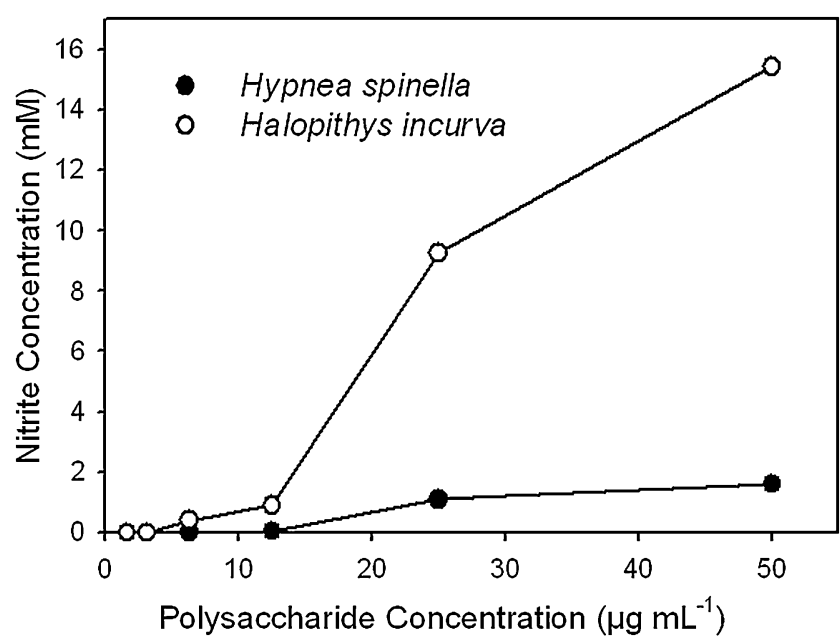

Fig. 3 Production of nitric oxide (NO) by RAW macrophages exposed to different concentrations of polysaccharides from Hypnea spinella and Halopithys incurva. Data points represent the average of three samples \pm SD. Error bars not shown are smaller than the symbol size

The comparison with the library data from Thermo Fischer Scientific showed that the polysaccharide fraction from Hy. spinella was similar to Type III kappa carrageenan (90\%). In contrast, the polysaccharides from $H$. incurva were similar to pullulan P800 (86\%). Carrageenan is a high-molecular-weight sulfated polygalactan consisting of D-galactose and 3,6-anhidro D-galactose linked by $\alpha(1-3)$ and $\beta(1-4)$ bonds. The use of carrageenan as a food texture enhancer has increased markedly during the last half century; however, this polysaccharide is also known to induce inflammation in rheumatological and intestinal models of colitis Borthakur et al. (2007). It has been demonstrated that exposure of human intestinal epithelial cells to carrageenan triggers a distinct inflammatory pathway via activation of Bcl10 with NF-kappa $\beta$ activation and the upregulation of IL-8 secretion (Yuan et al. 2006). In contrast to carrageenan, pullulan is an $\alpha-(1-6)$ maltotriose water-soluble polymer produced from starch by fermentation. The most important use of pullulan is for the manufacture of edible films and capsules for the pharmaceutical and nutraceutical industry. While pullulan is considered a neutral product in the pharmaceutical industry, pullulan derivates, such as cholesteryl group-bearing pullulan (CHP), have been reported as an efficient device to deliver tumor antigen peptides (Gu et al. 1998). In fact, CHP-HER2 is a novel protein antigen vaccine that elicits 146HER2-specific CD8(+) and CD4(+) $\mathrm{T}$ cell immune responses in patients with HER2-expressing tumors (Kageyama et al. 2008). As a result, CHP is being tested for its induction of specific humoral and cellular immune responses in different types of cancer, such as melanoma (Tsuji et al. 2008). 
Their similar biochemical composition to that of pullulan, as well as their effect on the production of NO and IL- 6 by RAW macrophages, suggests that the polysaccharides from $H$. incurva might also induce cellular immune response. Polysaccharides from a number of seaweed (Schepetkin and Quinn 2006; Castro et al. 2006) and higher plants (Pereira et al 2000; Cheng et al 2007) have been reported to enhance phagocytic and secretory activity of macrophages and phagocytes. The polysaccharides from Porphyra yezoensis, for example, induced the in vitro and in vivo production of NO and TNF- $\alpha$ by murine macrophages (Yoshizawa et al. 1993). Acid polysaccharides from the green alga Ulva rigida induced respiratory burst activity and the expression of IL-1 $\beta$ in turbot kidney and peritoneal leucocytes. This effect was lost after desulfation of the polysaccharides, indicating that the sulfate groups are required for induction of turbot innate immune response by $U$. rigida polysaccharides (Castro et al. 2006). Similarly, Leiro et al. (2007) demonstrated that the incubation of RAW macrophages with $U$. rigida polysaccharides induced an increase in nitrite production, although this effect decreased considerably after desulfation of polysaccharides, suggesting that the sulfate group is important for macrophage activation. Similarly, other studies have demonstrated that the highsulfate-containing exopolysaccharide $\mathrm{p}-\mathrm{KG} 03$ produced by the red-tide microalga Gyrodinium pudicum strain KG03 increased the production of macrophage cytokines, such as IL-1 $\beta$ and -6 , and TNF- $\alpha$ (Yim et al. 1993). Our results indicate that $H$. incurva polysaccharides induce cytokine release comparable in amplitude to that observed for LPS, which is a strong cytokine inducer. It has been reported that carrageenan, a polysaccharide similar to those from $H y$. spinella, shows antitumor and immunomodulating activities (Zhou et al. 2004). Carrageenan was shown to stimulate the generation of superoxide, PMNs, and the secretion of TNF$\alpha$ from macrophages (Shibata et al. 2000). Similarly, there are reports about constituents of the red alga Gracillaria verrucosa that indicate its anti-inflammatory activity determined by their inhibitory effects on the production of the same pro-inflammatory mediators (NO, IL-6, and TNF$\alpha$; Dang et al. 2008). Our results, however, do not agree with this observation; in fact, the polysaccharides from $H y$. spinella did not induce TNF- $\alpha$ production at the tested concentrations.

In addition, high molecular weight polysaccharide preparations isolated from food-grade microalgae have been described as potent activators of human monocytes/macrophages: "Immulina" from Spirulina platensis, "Immunon" from Aphanizomenon flos-aquae, and "Immurella" from Chlorella pyrenoidosa (Pugh et al. 2001). Each of these polysaccharides substantially increased mRNA levels of IL$1 \beta$ and TNF- $\alpha$, and they are between 100 and 1,000 times more active for in vitro monocyte activation than polysac- charide preparations that are currently used clinically for cancer immunotherapy.

Though there is a lack of knowledge regarding the molecular mechanisms involved in macrophage activation by algal polysaccharides, it has been suggested that this immune function could be similar to that observed for plant and mushroom-derived polysaccharide structures (Schepetkin and Quinn 2006). The results from our study suggest that the polysaccharides from $H y$. spinella and $H$. incurva could be considered for further studies as potential pharmaceutical products to be applied when macrophage activation is required.

Acknowledgments This paper was supported by grants from the Junta de Andalucía (AGR-0824) and from the Spanish Ministry of Education and Science (AGL2005-02655 and CGL2008-05407-C03-01) and Junta de Andalucía (RNM-295). We thank D. Rafael M. Sánchez (Thermo Electron Fisher), Dr. Ma. Ángeles Vargas, and Dr. Luis Alemany for their technical assistance in the FT-IR analysis.

\section{References}

Ainouz LI, Sampaio AH (1991) Screening of Brazilian marine algae for haemagglutinins. Bot Mar 34:211-214

Andrade CT, Azero EG, Luciano L, Gonzalves MP (2000) Rheological properties of mixtures of k-carrageenan from Hypnea musciformis and galactomannan from Cassia javanica. Int J Biol Macromol 27:349-353

Borthakur A, Bhattacharyya S, Dudeja PK, Tobacman JK (2007) Carrageenan induces interleukin- 8 production through distinct Bcl10 pathway in normal human colonic epithelial cells. Am J Physiol Gastrointest Liver Physiol 292:G829-G838

Castro R, Piazzon MC, Zarra I, Leiro J, Noya M, Lamas J (2006) Stimulation of turbot phagocytes by Ulva rigida C. Agardh polysaccharide. Aquaculture 254:9-20

Cheng A-C, Tu C-W, Chen Y-Y, Nan F-H, Chen J-C (2007) The immunostimulatory effects of sodium alginate and iotacarragenan on orange-spotted grouper Epinephelus coioides and its resistance against Vibrio alginolyticus. Fish Shellfish Immunol 22:197-205

Cordeiro RA, Gomes VM, Carvalho AFU, Melo VMM (2006) Effect of proteins from the red seaweed Hypnea musciformis (Wulfen) Lamouroux on the growth of human pathogen yeasts. Braz Arch Biol Technol 49:915-921

Dang HT, Lee HJ, Yoo ES, Shinde PB, Lee YM, Hong J (2008) Antiinflammatory constituents of the red alga Gracilaria verrucosa and their synthetic analogues. J Nat Prod 71:232-240

Davies LP, Jamieson DD, Baird-Lambert JA, Kazlauskas R (1984) Halogenated pyrrolopyrimidine analogues of adenosine from marine organisms: pharmacological activities and potent inhibition of adenosine kinase. Biochem Pharmacol 33:347-355

Desai V, Ramkrishnan R, Chintalwar G, Sainis KB (2007) G1-4A, an immunomodulatory polysaccharide from Tinospora cordifolia, modulates macrophage responses and protects mice against lipopolysaccharide induced endotoxic shock. Inter Immunopharmacol 7:1375-1386

González del Val A, Platas G, Basilio A, Cabello A, Gorrochate-Gui J, Suay I, Vicente F, Portillo E, Jimenez del Rio M, García-Reina 
G, Peláez F (2001) Screening of antimicrobial activities in red, green and brown macroalgae from Gran Canaria (Canary Islands, Spain). Int Microbiol 4:35-40

Gu XG, Schmitt M, Hiasa A, Nagata Y, Ikeda H, Sasaki Y, Akiyoshi K, Sunamoto J, Nakamura H, Kuribayashi K, Shiku H (1998) A novel hydrophobized polysaccharide/oncoprotein complex vaccine induces in vitro and in vivo cellular and humoral immune responses against HER2-expressing murine sarcomas. Cancer Res 58:3385-3390

Hori K, Myyazawa K, Fusetani N, Hashimoto K, Ito K (1986) Hypnins, low-molecular weight peptidic agglutinins isolated from a marine red alga, Hypnea japonica. Biochem Biophys Acta 873:228-236

Hori K, Matsubara K, Miyazawa K (2000) Primary structures of two hemagglutinins from the marine red alga, Hypnea japonica. Biochem Biophys Acta 1474:226-236

Kageyama S, Kitano S, Hirayama M, Nagata Y, Imai H, Shiraishi T, Akiyoshi K, Scott AM, Murphy R, Hoffman EW, Old LJ, Katayama N, Shiku H (2008) Humoral immune responses in patients vaccinated with 1-146 HER2 protein complexed with cholesteryl pullulan nanogel. Jap Can Ass 99:601-607

Kladi M, Vagias C, Roussis V (2004) Volatile halogenated metabolites from marine red algae. Phytochem Rev 3:337-366

Leiro J, Castro R, Arranz JA, Lamas J (2007) Immunomodulating activities of acidic sulphated polysaccharides obtained from the seaweed Ulva rigida C Agardh. Int Immunopharma 7:879-888

Martínez C, Delgado M, Pozo D, Leceta J, Calvo JR, Ganea D, Gomariz RP (1998) Vasoactive intestinal peptide and pituitary adenylate cyclase-activating polypeptide modulate endotoxininduced IL-6 production by murine peritoneal macrophages. J Leukoc Biol 63:591-601

Melo VMM, Medeiros DA, Rios FJB, Castelar LIM, Carvalho AFU (1997) Antifungal properties of proteins (agglutinins) from the red alga Hypnea musciformis (Wulfen) Lamouroux. Bot Mar 40:281-284

Mollet J, Rahaoui A, Lemoine Y (1998) J Appl Phycol 10:59-66

Morris Quevedo HJ, Martínez Manrique C, Abdala Díaz R, Cobas Pupo G (2000) Evidencias preliminares de la actividad inmunomoduladora de la fracción polisacárida de origen marino PC-1. Rev Cuba Oncol 16:171-176

Nagano CS, Debray H, Nascimento KS, Pinto VPT, Cavada BS, Saker-Sampaio S, Farias WRL, Sampaio AH, Calvete JJ (2005)
HCA and HML isolated from the red marine algae Hypnea cervicornis and Hypnea musciformis define a novel lectin family. Protein Sci 14:2167-2176

Pereira BMR, Da Silva B, Pereira N, Parente JOP (2000) Antiinflammatory and immunologically active polysaccharides of Periandra mediterranea. Phytochemistry 54:409-413

Pereira L, Amado AM, Critchley AT, van de Velde F, Ribeiro-Claro PJA (2009) Identification of selected seaweed polysaccharides (phycocolloids) by vibrational spectroscopy (FTIR-ATR and FTRaman). Food Hydrocolloids 23:1903-1909

Pugh N, Ross SA, El-Sohly HN, El-Sohly MA, Pasco DS (2001) Isolation of three high molecular weight polysaccharide preparations with potent immunostimulatory activity from Spirulina platensis, Aphanizomenon flos-aquae and Chlorella pyrenoidosa. Planta Med 67:737-742

Schepetkin I, Quinn M (2006) Botanical polysaccharides: macrophage immunomodulation and therapeutic potential. Int Immunophar 6:317-333

Shibata H, Kimura-Takagi I, Nagaoka M, Hashimoto S, Aiyama R, Iha M, Ueyama S, Yokokura T (2000) Properties of fucoidan from Cladosiphon okamuranus Tokida in gastric mucosal protection. Biofactors 11:235-245

Smit AJ (2004) Medicinal and pharmaceutical uses of seaweed natural products: a review. J Appl Phycol 16:245-262

Tsuji M, Suzuki K, Kitamura H, Maruya M, Kinoshita K, Ivanov II, Itoh K, Littman DR, Fagarasan S (2008) Requirement for lymphoid tissueinducer cells in isolated follicle formation and $\mathrm{T}$ cell-independent immunoglobulin A generation in the gut. Immunit 29:261-271

Yim JH, Son E, Pyo S, Lee HK (1993) Novel sulfated polysaccharide derived from red-tide microalga Gyrodinium impudicum strain KG03 with immunostimulating activity in vivo. Mar Biotechnol 7:331-338

Yoshizawa Y, Enomoto A, Todoh H, Ametani A, Kaminogawa S (1993) Activation of murine macrophages by polysaccharide fractions from marine algae (Porphyra yezoensis). Biosci Biotechnol Biochem 57:1862-1866

Yuan A, Chen JJ, Yao PL, Yang PC (2006) The role of interleukin-8 in cancer cells and microenvironment interaction. Front Biosci 10:853865

Zhou G, Sun Y, Xin H, Zhang Y, Li Z, Xu Z (2004) In vivo antitumor and immunomodulation activities of different molecular weight lambda-carrageenans from Chondrus ocellatus. Pharmacol Res 50:47-53 